\title{
Acceleration of sexual maturation in female rats by male stimulation
}

\author{
J. G. Vandenbergh \\ North Carolina Department of Mental Health, Research Division, \\ Raleigh, North Carolina 27611, U.S.A.
}

\begin{abstract}
Summary. In comparison to controls reared in isolation, female rats reared in the presence of an adult male from weaning attained puberty 5 days earlier when living in groups or almost 9 days earlier when living singly with a male. Accelerated sexual development occurred in the absence of accelerated physical growth.
\end{abstract}

The process of sexual maturation in the female rat is susceptible to modification by manipulation of environmental factors (Donovan \& van der Werff ten Bosch, 1965; Moltz, 1975). Rats reared in small litters and thus presumed to have access to a plentiful milk supply displayed coincident vaginal opening, first oestrus, and mating behaviour at a mean age of 38-41 days, but these measures were asynchronous in rats reared in large litters and occurred an average of 5-10 days later in life (Kennedy \& Mitra, 1963). Chronic underfeeding after weaning induces similar delays in reproductive maturation (Kennedy \& Mitra, 1963; Widdowson, Mavor \& McCance, 1964) but attempts to accelerate the onset of puberty by providing a high-protein diet proved unsuccessful (Mandl \& Zuckerman, 1952). Factors which have been shown to accelerate sexual maturation in rats include exposure to continuous light (Relkin, 1968), birth in summer rather than in winter (Ramaley \& Bunn, 1972), and exposure to cold (Mandl \& Zuckerman, 1952).

In female mice, stimuli from males accelerate and stimuli from females inhibit the rate of sexual maturation (Vandenbergh, 1967, 1973; Kennedy \& Brown, 1970; Cowley \& Wise, 1972). Since the rat has been the animal most commonly chosen for experiments designed to unravel the physiological basis for puberty (Donovan \& van der Werff ten Bosch, 1965; Moltz, 1975), it seemed worthwhile to determine whether the process of sexual maturation in the female rat is also susceptible to male stimulation.

Adult, Holtzman rats of both sexes were purchased in December and mated after 1 week of acclimatization to the laboratory to produce the animals used in this study. On the 2nd day after birth all litters were reduced to $8-10$ young by preferentially discarding males, but at least one male was left in each litter. The young were weaned at 21 days of age and all females were weighed and placed in one of four groups by split-litter assignment. Treatments were then randomly assigned to each of the groups as follows: Group 1, isolated females; Group 2, females caged singly with a male; Group 3, females grouped four to a cage; and Group 4, females grouped four to a cage with a male present. The males used were adults of proven fertility. All animals were housed in $45 \times 23 \times 15 \mathrm{~cm}$ cages and freely provided with Purina rat chow and tap water. Two rooms with separate air-exchange systems were used, one for Groups 2 and 4 and one for Groups 1 and 3. Each room was on a 14-hr light: 10 -hr dark lighting schedule and was maintained at $22 \pm 3^{\circ} \mathrm{C}$ with relative humidity held between 30 and $70 \%$. All measures were subjected to analysis of variance and comparisons were made by the LSD procedure (Sokal \& Rohlf, 1969).

Each animal was examined daily for vaginal opening. When the vagina was found to be perforate, body weight was recorded and a vaginal lavage was taken daily thereafter until either full cornification of the vaginal epithelium was detected, the female displayed a seminal plug in the vagina, spermatozoa were detected, or in a few cases obvious signs of pregnancy were noted. In the last event pregnancy was allowed to go to term and first oestrus was considered to have occurred 21 days before parturition. 
Table 1. The mean age ( $t$ S.E.M.) of female rats at vaginal opening and first oestrus following exposure to males when females are caged singly (Groups 1 and 2) or as a group of four (Groups 3 and 4) and the mean body weight $( \pm$ S.E.M.) of females at weaning and vaginal opening

\begin{tabular}{|c|c|c|c|c|}
\hline & $\begin{array}{c}\text { Group 1 } \\
\text { (Isolated, no male) }\end{array}$ & $\begin{array}{c}\text { Group } 2 \\
\text { (Isolated+male) }\end{array}$ & $\begin{array}{c}\text { Group } 3 \\
\text { (Grouped, no male) }\end{array}$ & $\begin{array}{c}\text { Group 4 } \\
\text { (Grouped+male) }\end{array}$ \\
\hline No. of cages & 15 & 14 & 15 & 15 \\
\hline \multicolumn{5}{|l|}{ Age (days) } \\
\hline At vaginal opening & $35 \cdot 9 \pm 1 \cdot 19$ & $35.9 \pm 0.94$ & $35 \cdot 6 \pm 0.45$ & $36 \cdot 1 \pm 0.50$ \\
\hline At first oestrus & $45 \cdot 1 \pm 1 \cdot 62$ & $36.5 \pm 0.83$ & $44.9 \pm 0.69$ & $39.8 \pm 1.04$ \\
\hline \multicolumn{5}{|l|}{ Body weight (g) } \\
\hline At weaning & $51 \cdot 2 \pm 1 \cdot 72$ & $51.8 \pm 1.48$ & $49 \cdot 4 \pm 1 \cdot 13$ & $50 \cdot 1 \pm 1 \cdot 14$ \\
\hline At vaginal opening & $116 \cdot 2 \pm 4 \cdot 21$ & $124 \cdot 0 \pm 5 \cdot 02$ & $118 \cdot 5 \pm 2 \cdot 20$ & $123.4 \pm 3.01$ \\
\hline
\end{tabular}

No differences in the age at vaginal opening were noted among any of the treatments (Table 1 ). An analysis of variance for first oestrus showed a highly significant $(P<0.0001)$ effect of the male's presence. Isolated females reared in the presence of a male attained first oestrus an average of 8.6 days earlier $(P<0.01)$ than those reared without a male present. Similarly, the females in groups showed first oestrus 5.1 days earlier $(P<0 \cdot 01)$ when a male was present than in the absence of a male. The overall effect of grouping was not significant, but comparing the results for Groups 2 and 4 showed that grouping did result in a significant delay in first oestrus $(P<0 \cdot 01)$.

The body weight of females reared under all treatments was similar at weaning (Table 1) and no significant differences in weight at vaginal opening or in growth rate to the age of vaginal opening was detected. Females appeared to grow more rapidly in the presence of a male but the differences were not significant $(P<0 \cdot 10)$.

A potential for bias exists in these data because five indices were used to determine sexual maturation in the male-exposed groups, three of them (seminal plug, spermatozoa in vagina, and conception) were at least partly a function of the male, and only two indices (vaginal opening and vaginal cornification) were common to all groups. With few exceptions our evaluation of vaginal cornification accurately predicted the date of conception. Of 60 females housed with males in groups, 53 became pregnant. Of these 53 females, 5 displayed a seminal plug on the day of vaginal opening and thus a vaginal lavage was unobtainable. Among the remaining 48 females, the day of conception was accurately predicted from the presence of a cornified vaginal smear. Similarly, among females housed alone with a male all 14 became pregnant. Six of these displayed a seminal plug on the day of vaginal opening and of the remainder vaginal cornification failed to signal conception in only one case. Thus it would seem that the potential for bias was trivial.

Mouse studies have shown that the presence of females can inhibit the sexual maturation of other females (Vandenbergh, 1973). Grouped female mice attain puberty 11 days later than isolated females in the presence of a male and 19 days later when male influences are excluded. This delay in puberty may also be due to chemical stimuli because isolated female mice exposed to bedding material soiled by a group of females show retarded sexual development (Drickamer, 1974). In the rat, the female inhibitory effect was only revealed when females were in the presence of males and the magnitude of the effect is considerably less than in mice.

In the mouse, much of the acceleratory effect of the male on female sexual maturation can be ascribed to a pheromone found in male urine (Cowley \& Wise, 1972; Colby \& Vandenbergh, 1974; Vandenbergh, Whitsett \& Lombardi, 1975). In these earlier studies it was found that urine produced by male rats significantly accelerated sexual development of female mice. It is possible therefore that urine from male rats contains a substance which is capable of inducing accelerated maturation of female rats and that this substance is similar to that found in the urine of male mice.

I thank Dr J. J. van der Werff ten Bosch who encouraged me to conduct pilot studies in his laboratory. Ms Carol Bradley and Mr Joseph Lombardi provided valuable technical assistance. This work was supported by a grant from the U.S. Public Health Service (MH 16870). 


\section{References}

Colby, D.R. \& VANDENBERGH, J.G. (1974) Regulatory effects of urinary pheromones on puberty in the mouse. Biol. Reprod. 11, 268-279.

Cowley, J.J. \& Wise, D.R. (1972) Some effects of mouse urine on neonatal growth and reproduction. Anim. Behav. 20, 499-506.

Donovan, B.T. \& VAN DER WeRFF TEN BOSCh, J.J. (1965) Physiology of Puberty. Williams and Wilkins, Baltimore.

Drickamer, L.C. (1974) Sexual maturation of female house mice: social inhibition. Devl Psychobiol. 7, 257-265.

KenNedy, G.C. \& Mitra, J. (1963) Body weight and food intake as initiating factors for puberty in the rat. J. Physiol., Lond. 166, 408-418.

KenNedY, J.M. \& Brown, K. (1970) Effects of male odor during infancy on the maturation, behavior, and reproduction of female mice. Devl Psychobiol. 3, 179-189.

MANDL, A.M. \& ZuCKerman, S. (1952) Factors influencing the onset of puberty in albino rats. J. Endocr. 8, 357-364.

Moltz, H. (1975) The search for the determinants of puberty in the rat. In Hormonal Correlates of
Behavior, pp. 35-154. Eds B. E. Eleftheriou \& R. L. Sprott. Plenum, New York.

RAMALEY, J.A. \& BUNN, E.L. (1972) Seasonal variations in the onset of puberty in rats. Endocrinology 91, 611-613.

RELKIN, R. (1968) Combined effects of hypothalamic lesioning and light in the advancement of puberty. Endocrinology 82, 1249-1250.

SOKAL, R.R. \& RoHLF, F.J. (1969) Biometry. W. H. Freeman, San Francisco.

VANDENBERGH, J.G. (1967) Effect of the presence of a male on the sexual maturation of female mice. Endocrinology 81, 345-349.

VANDENBERGH, J.G. (1973) Acceleration and inhibition of puberty in female mice by pheromones. $J$. Reprod. Fert., Suppl. 19, 411-419.

VANDENBERGH, J.G., WhitSETT, J.M. \& LOMBARDY, J.R. (1975) Partial isolation of a pheromone accelerating puberty in female mice. J. Reprod. Fert. 43, 515523.

Widdowson, E.M., Mavor, W.O. \& MCCANCE, R.A. (1964) The effect of undernutrition and rehabilitation on the development of the reproductive organs. J. Endocr. 29, 119-126.

Received 18 August 1975 